\title{
Prediction Model of Cutting Parameters for Turning High Strength Steel Grade-H: Comparative Study of Regression Model versus ANFIS
}

\author{
Adel T. Abbas, ${ }^{1}$ Mohanad Alata, ${ }^{1}$ Adham E. Ragab, ${ }^{2}$ \\ Magdy M. El Rayes, ${ }^{1}$ and Ehab A. El Danaf ${ }^{1}$ \\ ${ }^{1}$ Department of Mechanical Engineering, College of Engineering, King Saud University, P.O. Box 800, Riyadh 11421, Saudi Arabia \\ ${ }^{2}$ Department of Industrial Engineering, College of Engineering, King Saud University, P.O. Box 800, Riyadh 11421, Saudi Arabia \\ Correspondence should be addressed to Adel T. Abbas; atabbas1954@yahoo.com
}

Received 5 January 2017; Revised 27 February 2017; Accepted 2 March 2017; Published 22 March 2017

Academic Editor: Fernando Lusquiños

Copyright @ 2017 Adel T. Abbas et al. This is an open access article distributed under the Creative Commons Attribution License, which permits unrestricted use, distribution, and reproduction in any medium, provided the original work is properly cited.

\begin{abstract}
The Grade-H high strength steel is used in the manufacturing of many civilian and military products. The procedures of manufacturing these parts have several turning operations. The key factors for the manufacturing of these parts are the accuracy, surface roughness $\left(R_{a}\right)$, and material removal rate (MRR). The production line of these parts contains many CNC turning machines to get good accuracy and repeatability. The manufacturing engineer should fulfill the required surface roughness value according to the design drawing from first trail (otherwise these parts will be rejected) as well as keeping his eye on maximum metal removal rate. The rejection of these parts at any processing stage will represent huge problems to any factory because the processing and raw material of these parts are very expensive. In this paper the artificial neural network was used for predicting the surface roughness for different cutting parameters in CNC turning operations. These parameters were investigated to get the minimum surface roughness. In addition, a mathematical model for surface roughness was obtained from the experimental data using a regression analysis method. The experimental data are then compared with both the regression analysis results and ANFIS (Adaptive Network-based Fuzzy Inference System) estimations.
\end{abstract}

\section{Introduction}

High strength steel is widely used in industrial civilian and military products. Many grades of high strength steel are available based on its chemical composition and heat treatment procedures [1]. One of the famous military products that uses grade $(\mathrm{H})$ is the heavy cannons such as the Russian howitzer $122 \mathrm{~mm}$ and the 105 British cannon.

Using tungsten-carbide tools and employing multiobjective optimization, Abbas et al. [2] investigated the effect of various cutting parameters in turning of heat-treated alloy steel using tungsten-carbide tools. The experiments covered a practical range of studied parameters that allows maximizing material removal rate while keeping good surface quality within reasonable industrial limits.

In order to establish a model predicting surface roughness for AISI 1019 steel machined by turning, in which cutting speed, feed rate depth of cut, and nose radius were selected as the cutting variables, Bhardwaj et al. [3] employed response surface methodology (RSM) based on center composite rotatable design. The application of Box-Cox transformation improved the prediction of the model. In this work it was proven that the feed rate was the main affecting parameter on surface roughness, whereas the effect of cutting speed and feed rate was negligible.

The work conducted by Mokhtari Homami et al. [4] applied full factorial design analysis approach in which the flank wear and surface roughness were response variables whereas feed rate, cutting speed, tool nose radius, and approach angle were process variables. The authors concluded that approach angle, feed rate, and tool nose radius had a major influence on the surface roughness and tool flank wear. However, cutting speed individually affected the tool flank wear. The results showed that as the cutting speed 
increased, the surface quality was improved; however, the tool life was shortened due to excessive flank wear. Also, when the feed rate or approach angle increased, the surface roughness increased and the tool life decreased. They, also, concluded that the surface roughness increased with increasing nose radius and related this to the increased contact surface between the chip and the tool.

Svalina et al. [5] suggested evolutionary neurofuzzy system using multiobjective optimization of cutting parameters aiming for the minimum machining time as well as maximum metal removal rate while controlling the obtained surface roughness. Through their experimental investigation, they justified the application and further development of the suggested evolutionary neurofuzzy system for evaluation of surface roughness within the given constraints.

The influence of machining parameters on the chip shape classification was studied [6] using straight turning of mild steel (A500/A500M-13) and AISI 304 stainless steel, where the resulting chip shapes were evaluated. Adaptive neurofuzzy inference system (ANFIS) was used in order to determine the inputs influence on the chip shape classification and also to estimate the most dominant factors which affect it. The inputs were, namely, cutting speed, feed rate, depth of cut, and surface roughness of the material. From results it was found that surface roughness has the highest influence on the chip shape classification. The obtained model could be used as optimal parameter settings for the best chip shape classification.

A fuzzy model was developed [7] for predicting the surface roughness at a given set of inputs, cutting speed, feed rate, and depth of cut representing realistic industrial environment. This model is capable of predicting the surface roughness for a given set of inputs helping the operator to select a set of working parameters that enables the setting of machining parameters to achieve a certain surface quality. For model verification, comparison between fuzzy output with the experimental data and an empirical model was built consequently. It was found that the experimental results were in good agreement with those predicted using the fuzzy model, where the system accuracy was 95\%, as applied experimentally under real operating conditions in milling of aluminum blocks.

For achieving minimum surface roughness through the prediction and optimization of machining parameters, Kant and Sangwan [8] presented an artificial neural network (ANN) technique coupled with genetic algorithm (GA). The predicted results are found to be close to the experimental values. They showed that the developed model outperforms the regression and fuzzy logic models. From modeling point of view, the ANN was validated as a prediction model which has statistically satisfactory prediction performance.

Raja et al. [9] applied Taguchi's L27 orthogonal array to investigate the surface roughness of AISI316 and AISI410 machined by CNC turning using different coated cutting tools in dry conditions. Analysis of variance (ANOVA) showed that linear feed rate and then quadratic feed rate are the most significant factors affecting surface quality. It was reported that TiAlN composition coated insets exhibited the best cutting performance compared to other inserts.
Chandrasekaran et al. [10] employed response surface methodology (RSM) to analyze the CNC turning of AISI 316 with multilayer coated $\mathrm{Ti}(\mathrm{C}, \mathrm{N}, \mathrm{B})$ and single layer coated with TiAlN cutting tool for different cutting conditions. The model predicted surface roughness and tool wear values fairly close to the experimental values. Feed rate, followed by the depth of cut, and quadratic depth of cut, followed by linear feed rate, were the most significant factors for surface roughness and tool wear, respectively, for the $\mathrm{Ti}(\mathrm{C}$, $\mathrm{N}, \mathrm{B}$ ) cutting tool. Feed rate, followed by interaction between feed rate and depth of cut, and quadratic depth of cut, followed by interaction of feed rate and depth of cut, were the most significant factors for surface roughness and tool wear, respectively, for TiAlN cutting tool.

Jafarian et al. [11] predicted surface roughness, resultant cutting forces, and tool wear by three artificial neural networks (ANN). They proposed a novel method for training the ANNs by using evolutionary algorithms rather than conventional methods that use backpropagation. The optimization was carried to minimize surface roughness and cutting forces and maximize tool life in turning process. Genetic algorithm (GA) and particle swarm optimization (PSO) were utilized to optimize each of the outputs, while the other outputs were kept in the suitable range. The obtained results showed that trained neural networks with genetic GA as optimization objective functions presented a powerful tool to analyze the effect of each parameter on the output model with high accuracy level.

D’Addona and Raykar [12] proposed using wiper inserts to achieve significantly better machined surface in hard turning process. The performance of wiper inserts in hard turning of oil hardened nonshrinking steel was investigated compared to conventional inserts. Analysis of variance (ANOVA) was used to examine the effect of four process parameters, namely, cutting speed, feed rate, depth of cut, and nose radius on surface roughness. The analysis showed the positive influence of wiper inserts on surface finish.

Acayaba et al. [13] applied Multiple Linear Regression and artificial neural network integrated with an optimization algorithm, known as simulated annealing (SA) methodologies to predict the minimum surface roughness for a set of cutting parameters in turning stainless steel at low cutting speeds. Neural network was reported to give better prediction compared to linear model by a fair margin. It was concluded that low speed results in a surface with higher roughness values due to built-up edge formation. In contrary, as speed increases the surface roughness improves, due to the low contact time between the chip and the tool.

Sahu and Choudhury [14] investigated the performance of multilayer TiN coated tool in machining of hardened steel (AISI 4340 steel) under high speed turning, which was also compared with that of uncoated tool. The influences of cutting parameters (speed, feed, and depth of cut) on surface roughness were analyzed using Taguchi methodology. It was reported that the machining of hard materials at higher speeds and lower feeds improved the surface roughness by using coated tools.

Agrawal et al. [15] developed three regression models, multiple regression, random forest, and quantile regression, 
to model the relation between surface roughness and several cutting parameters for dry turning of AISI 4340. It was concluded that the random forest regression model is a superior choice over multiple regression models for the prediction of expected surface roughness.

Azam et al. [16] investigated that the surface roughness is very important indicator to determine the surface quality of machined parts. Accurate predictive models for surface roughness will support the selecting of best machining parameters, to maximize the productivity without any deviation on quality. In this paper, an average surface roughness $\left(R_{a}\right)$ model has been developed for turning operation of high strength low-alloy steel using multilayer coated carbide tools. Multiple of tests was carried out to determine surface quality. The surface methodology (RSM) has been employed to develop a relationship between $R_{a}$ and machining parameters (feed, speed, and depth of cut). The feed rate has been noticed as the main parameter that affect the value of surface roughness. Contour plots of "feed versus speed" and "feed versus depth of cut" have a significant effect on $R_{a}$ value and can be achieved through optimal combination of cutting parameters. The accuracy of proposed model has been validated through the experimental data with average prediction of error $3.38 \%$.

In the paper of Mia and Dhar [17], the artificial neural network based on the predictive model of average surface roughness in turning operation of the hardened EN 24T steel has been predicted. The prediction was performed by using Neural Network Tool Box 7 of MATLAB R2015a for different levels of cutting conditions: cutting speed, feed rate, and different material hardness. The dry and high pressure cutting fluid jet environments were explored as cutting conditions. The experimental tests were carried out using full factorial design of experiment. Afterward the 3n-1, 3-n-2, and 4-n-1 ANN architectures were trained by utilizing the Levenberg-Marquardt, Bayesian regularization, and scaled conjugate gradient algorithms and evaluated based on the lowest root mean square error. The 3-10-1 and 3-42 ANN models, trained by Bayesian regularization, revealed the lowest root mean square error. A good fitting of the models was established by the regression coefficients higher than 0.997. Finally, the effect of cutting speed, feed, and hardness surface roughness at dry and high pressure cutting fluid conditions were studied. The high pressure cutting fluid leading to effective cooling and lubrication had the effect of reducing the surface roughness, whereas it was significantly increased when cutting hard materials because of the higher cutting forces arriving on the cutting tool.

Theoretical and empirical investigation were proposed by $\mathrm{He}$ et al. [18] to predict the surface finish obtained in a turning process using a diamond single-point tool in which the surface finish is considered to be composed of the defined and undefined parts. Theoretical formulation of the defined components such as the effects of the kinematics and minimum undeformed chip thickness were established. The undefined components in relation to the material spring back, plastic side flow, microdefects on the cutting edge of diamond tool, and others are empirically predicted by a RBF (radial basis function) neural network, which is established by
TABLE 1: Chemical composition for $\mathrm{H}$-steel material according to DEFSTAN 10-13/2005.

\begin{tabular}{lcccccccc}
\hline $\mathrm{C}$ & $\mathrm{Si}$ & $\mathrm{Mn}$ & $\mathrm{Ni}$ & $\mathrm{Cr}$ & $\mathrm{Mo}$ & $\mathrm{V}$ & $\mathrm{S}$ & $\mathrm{P}$ \\
\hline 0.30 & 0.17 & 0.46 & 2.86 & 0.76 & 0.47 & 0.01 & 0.002 & 0.006 \\
0.36 & 0.32 & 0.53 & 3.10 & 0.94 & 0.58 & 0.03 & 0.01 & 0.011 \\
\hline
\end{tabular}

referring to the experimental data. Finally, the particle swarm optimization algorithm is employed to find the optimum cutting conditions for the best surface finish. It was found that the optimization was satisfied through the experimental validation and the satisfactory level of prediction with an error of $0.59-10.11 \%$. This proves the effectiveness of the novel method used in surface roughness prediction.

In this paper a mathematical model for surface roughness was obtained from the experimental data using two techniques: regression analysis method and adaptive neurofuzzy inference system of MATLAB (ANFIS). These models have been validated using fifteen experimental runs that were not included in the regression analysis or in the ANFIS and a comparison between the two models is presented.

\section{Materials and Methods}

The material used in this work is high strength steel Grade$\mathrm{H}$, commercially known as "gun steel," which is normally used in the manufacturing of gun barrel and muzzle brake. The material is initially forged into cylindrical form and then annealed to remove residual stresses induced by forging. The cylinders are then deeply drilled and rough-machined to form the primary shape of gun barrel. Table 1 shows the chemical composition of high strength steel Grade- $\mathrm{H}$ according to UK ministry defense standard DEFSTAN 10$13 / 2005$ [1]. The heat treatment was carried out by heating the gun barrel to about $870^{\circ} \mathrm{C}$ for 4 hours before quenching in oil. This was immediately followed by a tempering procedure in which the sample was heated to $650^{\circ} \mathrm{C}$ over a period of 1.5 hours and maintained at this temperature for further 10 hours and then removed from the tempering furnace and cooled in air. The gun barrel is then ready for final machining. Table 2 shows the mechanical properties of Grade-H steel after heat treatment. The test samples were cut from the actual gun barrel from breech side (thick part) and machined to cylindrical shape in which they will be divided into five equally separated lengths, as shown in Figure 1, for conducting the turning runs.

EMCO Concept Turn 45 CNC lathe equipped with Sinumeric 840-D was used to conduct experimental work. An uncoated tungsten-carbide insert was used in the turning process. The insert and tool holder are SVJCL2020K16 and VCMT160404. The clearance angle, cutting edge angle, and nose radius were maintained at $7^{\circ}, 75^{\circ}$, and $0.4 \mathrm{~mm}$, respectively. Figure 2 shows the test rig for machining specimens. All cutting parameters were controlled via CNC part program. The test plan was implemented through 125 turning runs, in which the cutting speed, depth of cut, and feed rate had five levels each. Details of all testing conditions are provided in Table 3. TESA-Rugosurf-90 was used for 


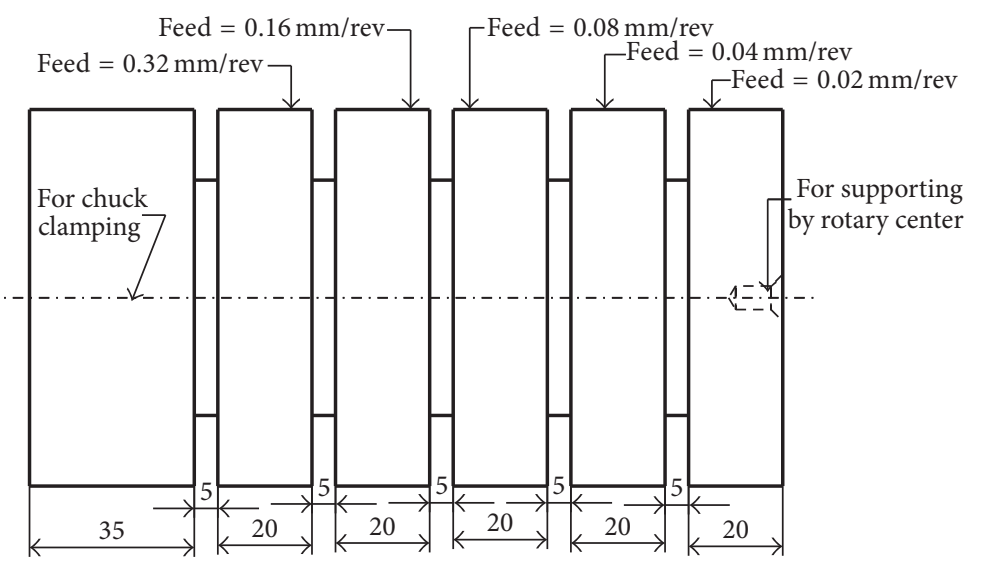

Figure 1: Test specimen drawing.

TABLE 2: Mechanical properties for $\mathrm{H}$-steel material according to DEFSTAN 10-13/2005.

\begin{tabular}{lc}
\hline Mechanical properties & Value \\
\hline Ultimate tensile strength & $>1200 \mathrm{~N} / \mathrm{mm}^{2}$ \\
$0.2 \%$ proof strength & $850-1000 \mathrm{~N} / \mathrm{mm}^{2}$ \\
Elongation $\%$ & $\geq 10 \%$ \\
Reduction of area & $>27 \%$ \\
Charpy at $\left(-40^{\circ} \mathrm{C}\right)$ & $\geq 24.4 \mathrm{~J}$ \\
Hardness & $32-38 \mathrm{HRc}$ \\
\hline
\end{tabular}

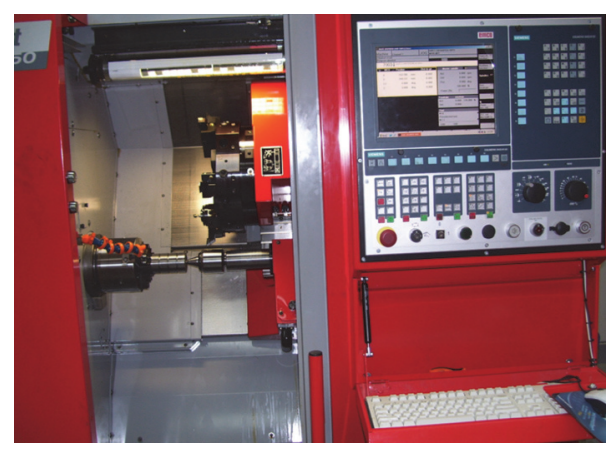

FIGURE 2: Test rig for samples machining.

surface roughness testing, where the test rig is shown in Figure 3. Full listing of all samples and the resulting measured surface roughness is provided in Appendix.

Full factorial experimental design was used to investigate the effect of three numerical factors (cutting speed, depth of cut, and feed rate) on the produced surface roughness. The studied range of each factor was divided into five levels creating 125 experiments. Regression was used to build the relation between surface roughness and studied factors. However, only 110 experimental readings were used for the regression, as 15 readings were excluded to be used for the sake of testing the predictability of the regression model. The 15 testing cases were selected such as to represent low, medium, and high levels of machining conditions in the experimental design. Material removal rate (MRR) was calculated using (1) for each

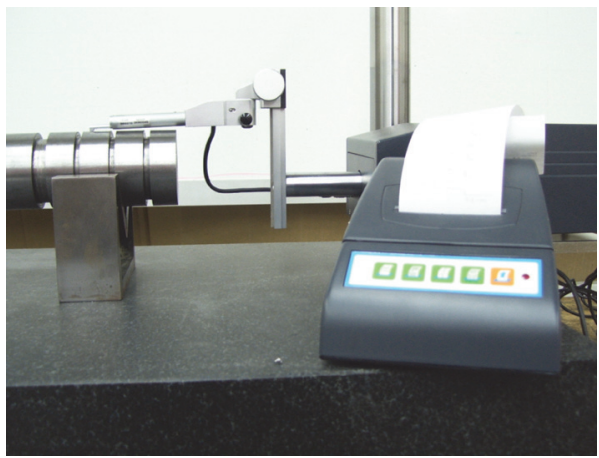

FIgURE 3: Test rig for measuring surface roughness.

run. Desirability function approach was used to maximize MRR maintaining $R_{a}$ below $0.8 \mu \mathrm{m}$ as a maximum limit for the surface roughness value.

$$
\operatorname{MRR}=1000 V * f_{r} * d
$$

where MRR is volume removed per unit time ( $\mathrm{mm}^{3} / \mathrm{min}$.), $V$ is the cutting speed $\left(\mathrm{m} / \mathrm{min}\right.$.), $f_{r}$ is the feed rate $(\mathrm{mm} / \mathrm{rev}$.), and $d$ is depth of cut ( $\mathrm{mm})$.

In fuzzy inference systems, all expert knowledge about the process is modeled by a set of rules. The set of rules has two parts: the antecedent part which covers all states of the system and the other part, the consequent one, which shows the resulting activities. Fuzzy systems may use neural networks as learning techniques. The numerical training data should be used in the hybrid network to learn the parameters and create the fuzzy rules to establish a linguistic model of the problem in hand. The Adaptive Neurofuzzy Inference System (ANFIS) is an algorithm to be used to create a fuzzy model from input/output data. In this paper, fuzzy inference system and ANFIS of MATLAB in Fuzzy Logic Toolbox are used to build a prediction model for surface roughness.

\section{Results and Discussions}

3.1. Regression Model. Minitab 17 multilinear regression analysis was used to build a mathematical model relating the 
TABLE 3: The cutting parameters and their levels used in experiments.

\begin{tabular}{lcccccc}
\hline Designation & Process parameter & Level 1 & Level 2 & Level 3 & Level 4 & Level 5 \\
\hline$A$ & Cutting speed $(\mathrm{m} / \mathrm{min})$ & 75 & 100 & 125 & 150 & 175 \\
$B$ & Depth of cut $(\mathrm{mm})$ & 0.15 & 0.30 & 0.45 & 0.60 & 0.75 \\
$C$ & Feed rate $(\mathrm{mm} / \mathrm{rev})$ & 0.02 & 0.04 & 0.08 & 0.16 \\
\hline
\end{tabular}

independent machining parameters (cutting speed, depth of cut, and feed rate) with the surface roughness represented by $R_{a}$. Stepwise technique was used to eliminate the insignificant terms from the model. The model was fitted in the form given by (2) [19]:

$$
\begin{aligned}
R_{a}=\beta_{o} & +\sum_{i=1}^{k} \beta_{i} X_{i}+\sum_{i=1}^{k} \beta_{i i} X_{i}^{2} \\
& +\sum \sum_{i<j} \beta_{i j} X_{i} X_{j} \\
& +\sum \sum_{i<j<k} \beta_{i j k} X_{i} X_{j} X_{k} \\
& +\sum \sum_{i \neq j} \beta_{i i j} X_{i}^{2} X_{j}+\epsilon_{i},
\end{aligned}
$$

where $\beta_{o}$ is the constant term, $\beta_{i}$ represents the linear effects, $\beta_{i i}$ represents the pure quadratic effects, $\beta_{i j}$ represents the second-level interaction effects, $\beta_{i j k}$ represents the third-level interaction effects, $\beta_{i i j}$ represents the effect of interaction between linear and quadratic terms, and $\epsilon_{i}$ represents the error in predicting experimental surface roughness.

Equation (3) represents the regression analysis fitted model. The adequacy of the model fit, measured by the coefficient of determination (adjusted $R$-squared), was calculated as 0.999 showing that $99 \%$ of the variability in $R_{a}$ readings is explained by the fitted model. The predicted $R$ square was calculated as 0.999 , proving that the model is not overfitted and has a good predictability. Figure 4 shows a scatter plot for the predicted $R_{a}$ versus the measured $R_{a}$. It is clear from the figure that the relation between them is linear. Anderson-Darling test was conducted to check the normality of residuals with a result of $p$ value $=0.163>0.05$ assuming normally distributed residuals.

$$
\begin{aligned}
R_{a}= & 0.0614-0.00301 A+0.012 B \\
& +6.331 C+0.000008 A^{2}+0.299 B^{2} \\
& +1.878 C^{* 2}+0.001924 A B \\
& +0.030293 A C+5.195 B C \\
& -3.995 B^{2} C .
\end{aligned}
$$

Optimization process was run using the desirability function approach to maximize the material removing rate (MRR) while maintaining $R_{a}$ below $0.8 \mu \mathrm{m}$. The results, illustrated in Figure 5, show that the maximum expected MRR equals $5668 \mathrm{~mm}^{3} / \mathrm{min}$. and happens at these machining conditions: cutting speed of $175 \mathrm{~m} / \mathrm{min}$., depth of cut of $0.75 \mathrm{~mm}$, and feed rate of $0.043 \mathrm{~mm} / \mathrm{rev}$ while maintaining $R_{a}$ at about $0.79 \mu \mathrm{m}$.

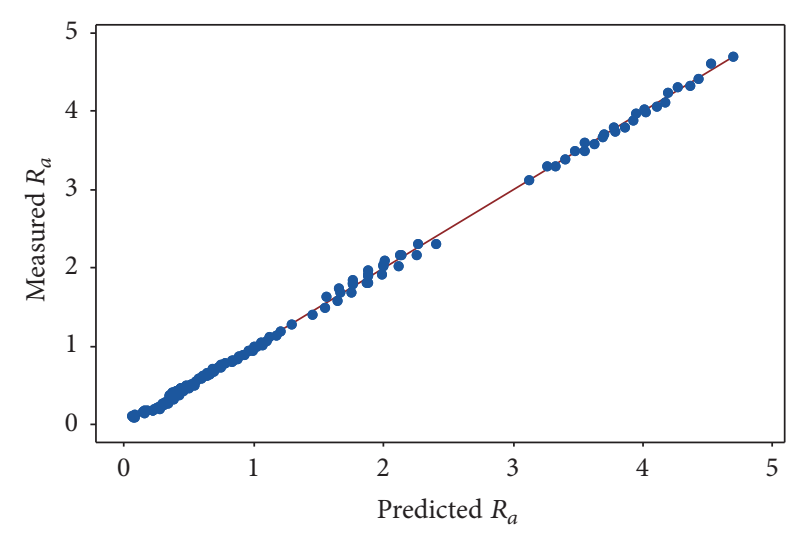

FIGURE 4: Scatter plot of measured $R_{a}$ versus predicted $R_{a}$.

3.2. Fuzzy Inference System. A fuzzy inference system is basically described in Figure 6.

Fuzzy inference system can be classified into three types: Tsukamoto type (also called type 1), Mamdani type (also called type 2), and Sugeno type (also called Takagi-Sugeno type, Takagi-Sugeno-Kang type, and type 3). Most of the differences among these types come from the specification of the consequent part. Sugeno type fuzzy inference system is extremely suitable for smoothly interpolating linear gains applied across an input space; it is a natural and efficient gain scheduler. Similarly, it is also suited for modeling nonlinear systems by interpolating between multiple linear models.

Fuzzy inference process consists of the following steps: (1) fuzzification, (2) application of fuzzy operation in the antecedent, (3) implication to the consequent, (4) aggregation, and (5) defuzzification. Figure 7 describes how these steps are performed for the three different types of fuzzy inference system.

Firstly, crisp data input is converted into fuzzy form through fuzzification. The fuzziness is determined by the membership function used. If the antecedent part (also called premise part) has more than one input, fuzzy operation using AND (intersection) and/or OR (union) is applied. AND operation can be conducted using T-norm operators such as minimum or product, whereas OR operation can be conducted using T-conorm (also called S-norm) operators such as maximum or probabilistic OR. Implication method is then applied to the results of the fuzzy operator. In Sugeno type fuzzy system, the fuzzy operation and the implication method are directly governed by its right hand side (RHS) equations which are mathematical functions of the inputs. The fuzzy operation followed by the implication method creates the consequent part of the fuzzy system. 


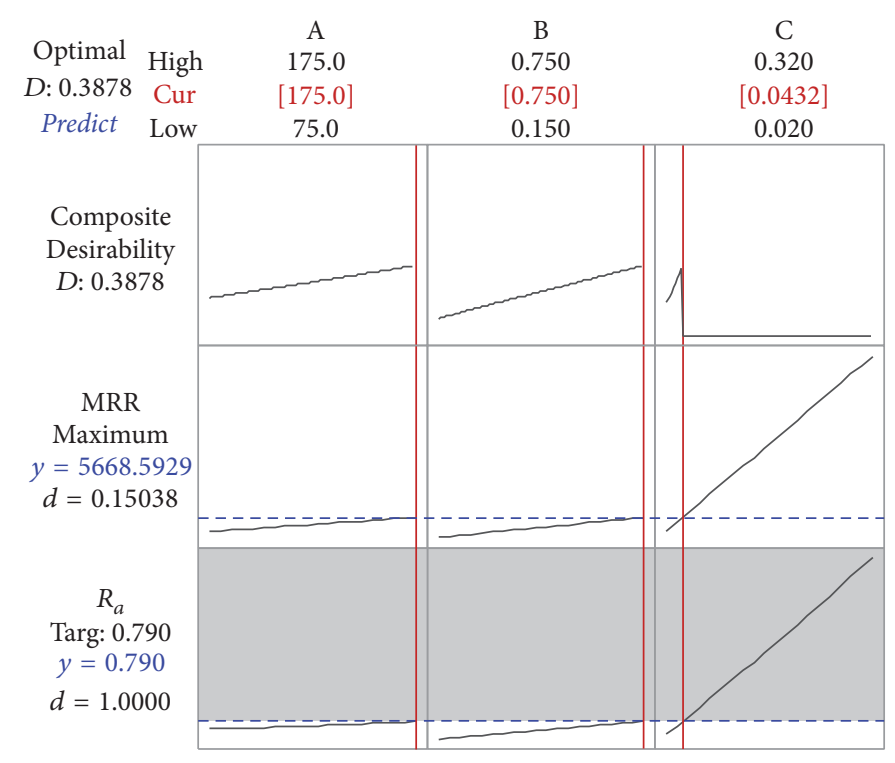

FIGURE 5: Optimization plot for $R_{a}$ and MRR.

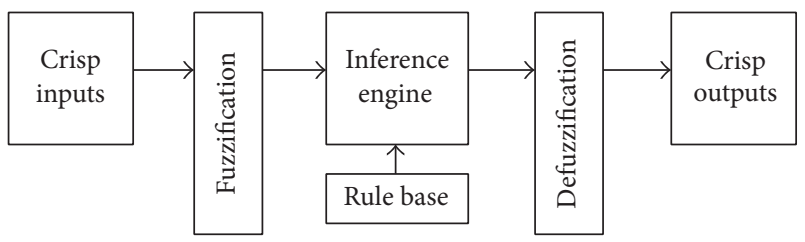

Figure 6: Fuzzy inference system.

After the implication step is accomplished for all of the rules, all of the consequents are combined into one value. This is called aggregation. In Mamdani type fuzzy system, the aggregation is conducted by using either maximum method, probabilistic OR method, or sum method, whereas the defuzzification is applied by using either centroid, bisector, middle of maximum, largest of maximum, or smallest of maximum method. In Sugeno type and Tsukamoto type fuzzy system, the aggregation-defuzzification is usually defined by the weighted average $\bar{z}$ given as follows:

$$
\bar{z}=\frac{\sum_{i=1}^{N} w_{i} z_{i}}{\sum_{i=1}^{N} w_{i}},
$$

where $z_{i}$ is the output of rule $i, w_{i}$ is firing strength of rule $i$, and $N$ is the number of rules.

3.3. Adaptive Network. Adaptive network is a special case of neural network with supervised-learning capability. After a training data (input-output data) is provided, the adaptive network will adjust its parameters (i.e., weights) in order to satisfy a certain termination criteria, usually number of iterations or error tolerance. The error is defined as the difference between the desired output and the output obtained from the learning process. The basic learning algorithm of the adaptive network to train the input-output data is steepest descent (backpropagation). In this learning algorithm, error is fed back to the network. The error signal originates from the output neuron of the network and it propagates backward in the network. The error signal eventually adjusts the weights. One iteration through all of the training data is called epoch. Number of epoch and the required error tolerance should be specified prior to the learning process.

To make the learning process faster, a hybrid learning algorithm which combines least square estimates (LSE) to the back propagation is usually used. Furthermore, the learning process can be done online or offline. In the online learning, the weights are updated based on the error signal of each input-output pair in the training data. Consequently, at each epoch, the number of adjustments is equal to the number of input-output pairs. In the offline learning, the weight adjustment is conducted based on the error signal of the entire training set. In other words, the weights are adjusted once only after all of the training data have been processed. The weights are only adjusted once at each epoch.

A typical architecture of adaptive network based on multilayer perceptron network is shown in Figure 8. It is a feedforward network with circle and square nodes. The circle nodes have fixed weight. On the other hand, the square nodes are adjustable weights which are updated during the learning process.

ANFIS combines the advantages of both the learning capability of an adaptive network and the modeling and approximation capabilities of a fuzzy inference system (FIS). Applying fuzzy inference system on a neural network frame, ANFIS has smoothness and learning capability at the same time. Given an input-output data, fuzzy rules are created through the learning process, and the FIS will interpolate (FIS is a universal approximate) among the rules to give smooth output. 


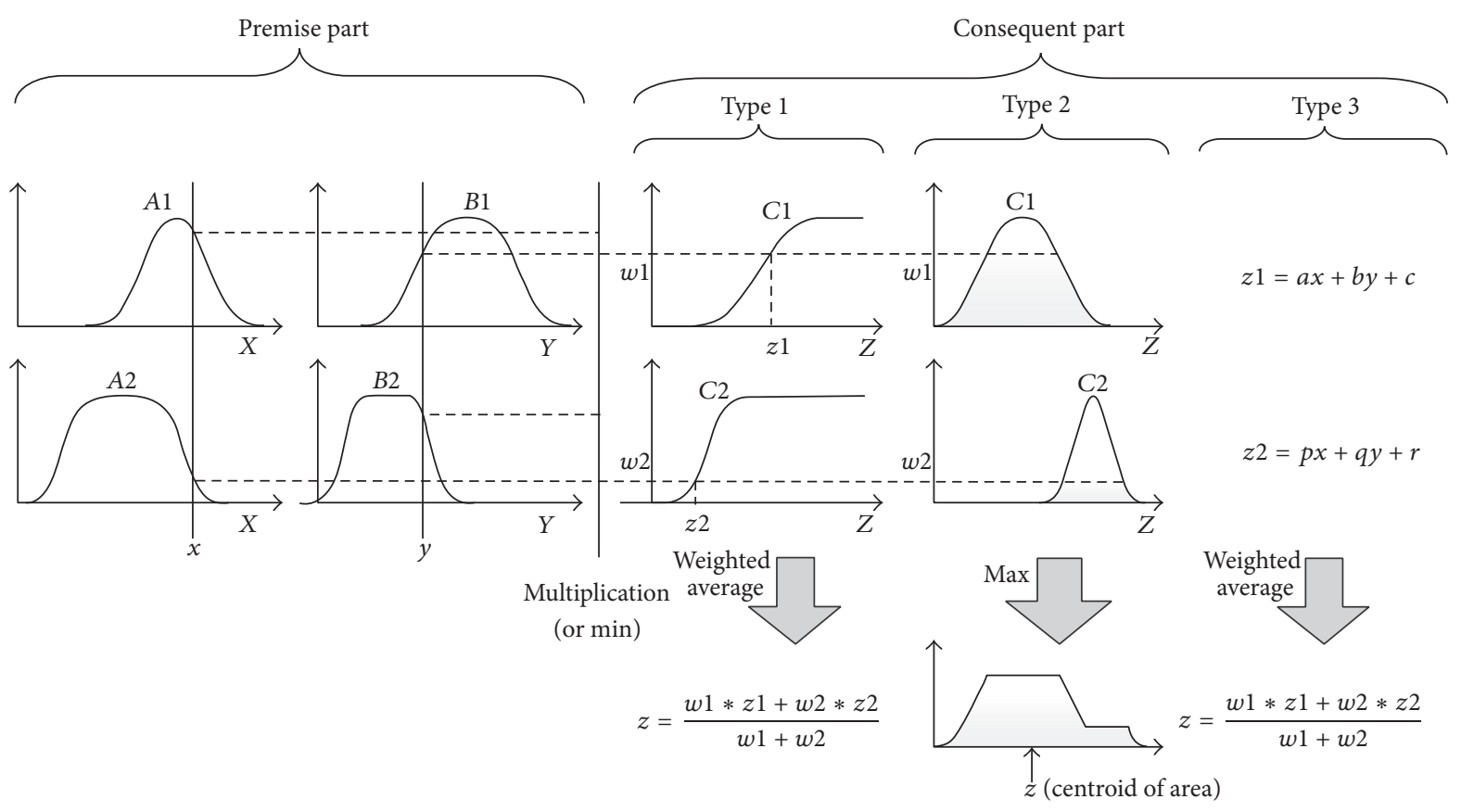

FIGURE 7: Fuzzy inference process for different types of fuzzy system.

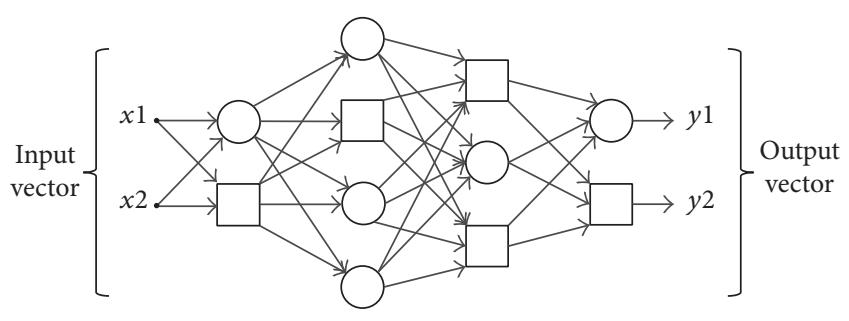

Figure 8: A typical adaptive network.

Figure 9 shows a two-input Sugeno type fuzzy model with two rules and its equivalent ANFIS model. The two rules states are as follows.

Rule 1. If $x$ is $A_{1}$ and $y$ is $B_{1}$ then $f_{1}=p_{1} x+q_{1} y+r_{1}$.

Rule 2. If $x$ is $A_{2}$ and $y$ is $B_{2}$ then $f_{2}=p_{2} x+q_{2} y+r_{2}$.

In the ANFIS model [20], nodes in the same layers are of the same function family. Subscript $i$ represent a rule. As in this example there are 2 rules; $i$ are positive integers from 1 to 2 . Every node $i$ in layer 1 has a node function which represents its membership function. Each node contains parameters called premise parameters. These parameters define the shape of the membership function. Circle nodes in layer 2 serve as fuzzy operators which can be T-norm or T-conorm operators, depending on how the inputs in the antecedent are connected. As the inputs in this example are connected by AND operation, any T-norm operator such as minimum or product can be applied in the circle nodes. Each circle node in layer 2 represents the firing strength of a rule. In layer 3, each circle node calculates the ratio of the $i$ th rule's firing strength $w_{i}$ to the sum of all rules' firing strengths. The ratio, therefore, is called normalized firing strength $\bar{w}_{i}$. As in this example there are two rules; the normalized firing strength is given by

$$
\bar{w}_{i}=\frac{w_{i}}{w_{1}+w_{2}} .
$$

In layer 4 , each square node multiplies the normalized firing strength by its corresponding consequent function. Hence, the output of the square node is given by

$$
O_{i}^{4}=\bar{w}_{i} f_{i}=\bar{w}_{i}\left(p_{i} x+q_{i} y+r_{i}\right),
$$

where $p_{i}, q_{i}$, and $r_{i}$ are called consequent parameters.

Layer 5 represents the aggregation. In this layer, a circle node labeled $\Sigma$ computes the weighted average as given in (1).

According to Jang [20], learning in ANFIS may use backpropagation algorithm. In MATLAB, the default option is the hybrid learning of backpropagation and least squares estimation (LSE). The hybrid learning converges faster compared to only backpropagation. In the hybrid learning, the set of parameters consists of nonlinear antecedent parameters and linear consequent parameters. Each epoch in the learning process is composed of forward pass and backward pass. In the forward pass, the node outputs are calculated layer by layer, until layer 4 . In this pass, the nonlinear antecedent parameters are fixed while the linear consequent parameters are computed using LSE. In the backward pass, the error is sent back through the network. In this pass, the linear consequent parameters are fixed while the nonlinear antecedent parameters are computed using backpropagation. Table 4 summarizes these learning procedures. Table 5 summarizes the information of ANFIS for the surface roughness model. 


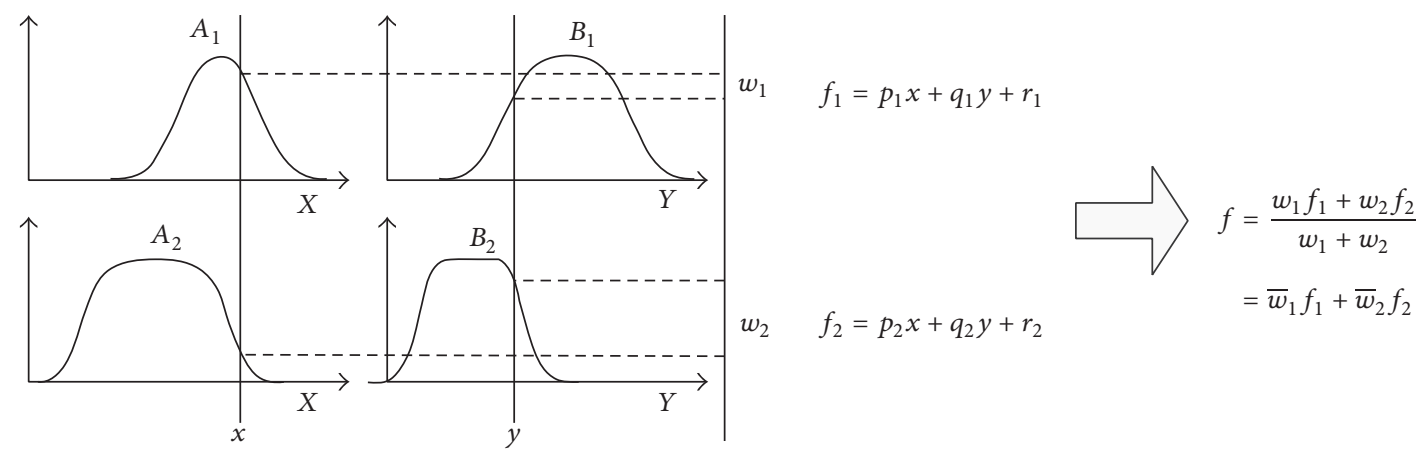

(a)

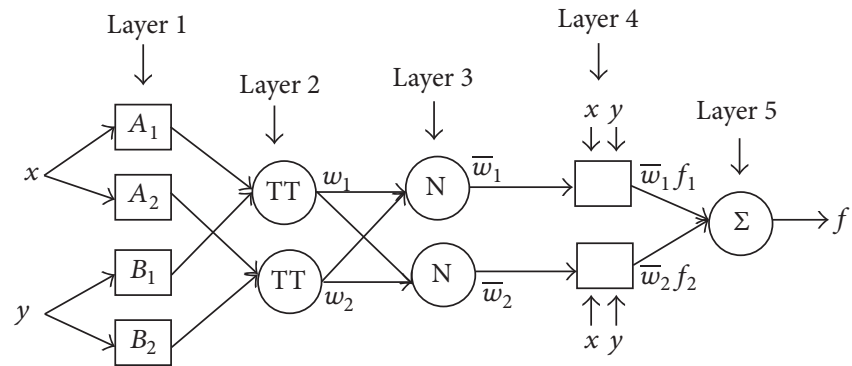

(b)

FIGURE 9: (a) A Sugeno type fuzzy model and (b) its equivalent ANFIS architecture.

TABLE 4: Two passes in the hybrid learning of ANFIS.

\begin{tabular}{lcc}
\hline & Forward pass & Backward pass \\
\hline Nonlinear premise parameters & Fixed & Back propagation \\
Linear consequent parameters & LSE & Fixed \\
Signals & Node outputs & Error signals \\
\hline
\end{tabular}

TABLE 5: ANFIS information.

\begin{tabular}{lc}
\hline $\begin{array}{l}\text { Number of inputs } \\
\text { Input MF }\end{array}$ & 3 (cutting speed, depth of cut, feed rate) \\
"gbellmf" \\
Number of outputs \\
Output type \\
$\begin{array}{l}\text { Number of fuzzy rules } \\
\text { Number of input-output } \\
\text { pairs (training data) }\end{array}$ \\
$\begin{array}{l}\text { Learning algorithm } \\
\text { Number of epochs }\end{array}$ \\
$\begin{array}{l}\text { Error tolerance } \\
\text { Evaluation method }\end{array}$ & 125 \\
\hline
\end{tabular}

3.4. Comparison. Fifteen experimental validation tests, not included in the regression analysis or in the ANFIS, were used to compare the predictability of both models. Table 6 illustrates the results of this comparison. Figure 10 shows a column chart illustrating the differences between measured $R_{a}$ and the predictions of regression and ANFIS in the fifteen runs. The table and the graph illustrate that there is a slight difference between the ANFIS and the regression predictions.

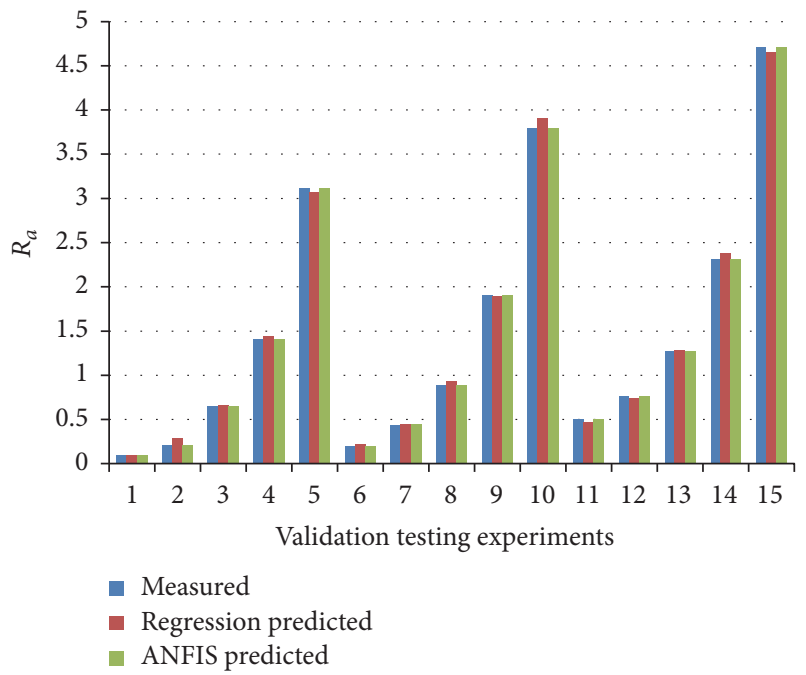

FIGURE 10: Column chart for measured $R_{a}$ versus predicted $R_{a}$.

However, the mean absolute error (MAE) of the regression analysis is one order of magnitude higher than the MAE of ANFIS analysis with values of $0.035 \mu \mathrm{m}$ and $0.003 \mu \mathrm{m}$, respectively.

\section{Conclusions}

Full factorial experimental design was used to examine the effect of three machining parameters (cutting speed, depth of cut, and feed rate) on the produced surface roughness. The studied range of each factor was divided into five levels 
TABLE 6: Comparison between regression model and ANFIS predictions.

\begin{tabular}{|c|c|c|c|c|c|c|c|}
\hline \multicolumn{3}{|c|}{ Machining parameters } & \multirow{2}{*}{ Measured $R_{a}(\mu \mathrm{m})$} & \multicolumn{2}{|c|}{ Regression model } & \multicolumn{2}{|c|}{ ANFIS } \\
\hline$A$ & $B$ & $C$ & & Predicted $R_{a}(\mu \mathrm{m})$ & Residual & Predicted $R_{a}(\mu \mathrm{m})$ & Residual \\
\hline 75 & 0.15 & 0.02 & 0.1 & 0.097 & 0.003 & 0.0996 & 0.0004 \\
\hline 75 & 0.15 & 0.04 & 0.212 & 0.286 & -0.074 & 0.212 & 0 \\
\hline 75 & 0.15 & 0.08 & 0.65 & 0.666 & -0.016 & 0.650 & 0 \\
\hline 75 & 0.15 & 0.16 & 1.415 & 1.446 & -0.031 & 1.410 & 0.005 \\
\hline 75 & 0.15 & 0.32 & 3.121 & 3.077 & 0.044 & 3.120 & 0.001 \\
\hline 125 & 0.45 & 0.02 & 0.203 & 0.218 & -0.015 & 0.197 & 0.006 \\
\hline 125 & 0.45 & 0.04 & 0.435 & 0.453 & -0.018 & 0.443 & -0.008 \\
\hline 125 & 0.45 & 0.08 & 0.893 & 0.928 & -0.035 & 0.889 & 0.004 \\
\hline 125 & 0.45 & 0.16 & 1.902 & 1.896 & 0.006 & 1.91 & -0.008 \\
\hline 125 & 0.45 & 0.32 & 3.792 & 3.903 & -0.111 & 3.79 & 0.002 \\
\hline 175 & 0.75 & 0.02 & 0.504 & 0.476 & 0.028 & 0.502 & 0.002 \\
\hline 175 & 0.75 & 0.04 & 0.767 & 0.744 & 0.023 & 0.769 & -0.002 \\
\hline 175 & 0.75 & 0.08 & 1.278 & 1.284 & -0.006 & 1.28 & -0.002 \\
\hline 175 & 0.75 & 0.16 & 2.318 & 2.382 & -0.064 & 2.32 & -0.002 \\
\hline 175 & 0.75 & 0.32 & 4.707 & 4.652 & 0.055 & 4.71 & -0.003 \\
\hline
\end{tabular}

TABLE 7: Full listing of experimental samples.

\begin{tabular}{|c|c|c|c|c|c|c|}
\hline Sample ID & Group & $\begin{array}{l}\text { Cutting speed } \\
(\mathrm{m} / \mathrm{min})\end{array}$ & $\begin{array}{l}\text { Depth of cut } \\
(\mathrm{mm})\end{array}$ & $\begin{array}{l}\text { Feed rate } \\
(\mathrm{mm} / \mathrm{rev})\end{array}$ & $\begin{array}{l}\text { Surface } R_{a} \\
\quad(\mu \mathrm{m})\end{array}$ & $\begin{array}{l}\text { Material removal rate (MRR) } \\
\qquad \mathrm{mm}^{3} / \mathrm{min}\end{array}$ \\
\hline 1 & & 75 & 0.15 & 0.020 & 0.100 & 225 \\
\hline 2 & & 75 & 0.15 & 0.040 & 0.212 & 450 \\
\hline 3 & 1 & 75 & 0.15 & 0.080 & 0.650 & 900 \\
\hline 4 & & 75 & 0.15 & 0.160 & 1.415 & 1800 \\
\hline 5 & & 75 & 0.15 & 0.320 & 3.121 & 3600 \\
\hline 6 & & 75 & 0.30 & 0.020 & 0.152 & 450 \\
\hline 7 & & 75 & 0.30 & 0.040 & 0.368 & 900 \\
\hline 8 & 2 & 75 & 0.30 & 0.080 & 0.738 & 1800 \\
\hline 9 & & 75 & 0.30 & 0.160 & 1.645 & 3600 \\
\hline 10 & & 75 & 0.30 & 0.320 & 3.312 & 7200 \\
\hline 11 & & 75 & 0.45 & 0.020 & 0.182 & 675 \\
\hline 12 & & 75 & 0.45 & 0.040 & 0.389 & 1350 \\
\hline 13 & 3 & 75 & 0.45 & 0.080 & 0.798 & 2700 \\
\hline 14 & & 75 & 0.45 & 0.160 & 1.699 & 5400 \\
\hline 15 & & 75 & 0.45 & 0.320 & 3.386 & 10800 \\
\hline 16 & & 75 & 0.60 & 0.020 & 0.261 & 900 \\
\hline 17 & & 75 & 0.60 & 0.040 & 0.499 & 1800 \\
\hline 18 & 4 & 75 & 0.60 & 0.080 & 0.898 & 3600 \\
\hline 19 & & 75 & 0.60 & 0.160 & 1.811 & 7200 \\
\hline 20 & & 75 & 0.60 & 0.320 & 3.599 & 14400 \\
\hline 21 & & 75 & 0.75 & 0.020 & 0.394 & 1125 \\
\hline 22 & & 75 & 0.75 & 0.040 & 0.599 & 2250 \\
\hline 23 & 5 & 75 & 0.75 & 0.080 & 0.999 & 4500 \\
\hline 24 & & 75 & 0.75 & 0.160 & 1.811 & 9000 \\
\hline 25 & & 75 & 0.75 & 0.320 & 3.678 & 18000 \\
\hline 26 & & 100 & 0.15 & 0.020 & 0.106 & 300 \\
\hline 27 & & 100 & 0.15 & 0.040 & 0.225 & 600 \\
\hline 28 & 6 & 100 & 0.15 & 0.080 & 0.688 & 1200 \\
\hline 29 & & 100 & 0.15 & 0.160 & 1.497 & 2400 \\
\hline 30 & & 100 & 0.15 & 0.320 & 3.311 & 4800 \\
\hline 31 & & 100 & 0.30 & 0.020 & 0.162 & 600 \\
\hline 32 & & 100 & 0.30 & 0.040 & 0.389 & 1200 \\
\hline 33 & 7 & 100 & 0.30 & 0.080 & 0.782 & 2400 \\
\hline 34 & & 100 & 0.30 & 0.160 & 1.743 & 4800 \\
\hline 35 & & 100 & 0.30 & 0.320 & 3.504 & 9600 \\
\hline
\end{tabular}


TABLe 7: Continued.

\begin{tabular}{|c|c|c|c|c|c|c|}
\hline Sample ID & Group & $\begin{array}{l}\text { Cutting speed } \\
(\mathrm{m} / \mathrm{min})\end{array}$ & $\begin{array}{l}\text { Depth of cut } \\
(\mathrm{mm})\end{array}$ & $\begin{array}{l}\text { Feed rate } \\
(\mathrm{mm} / \mathrm{rev})\end{array}$ & $\begin{array}{c}\text { Surface } R_{a} \\
(\mu \mathrm{m})\end{array}$ & $\begin{array}{l}\text { Material removal rate (MRR) } \\
\mathrm{mm}^{3} / \mathrm{min}\end{array}$ \\
\hline 36 & \multirow{5}{*}{8} & 100 & 0.45 & 0.020 & 0.193 & 900 \\
\hline 37 & & 100 & 0.45 & 0.040 & 0.412 & 1800 \\
\hline 38 & & 100 & 0.45 & 0.080 & 0.845 & 3600 \\
\hline 39 & & 100 & 0.45 & 0.160 & 1.798 & 7200 \\
\hline 40 & & 100 & 0.45 & 0.320 & 3.585 & 14400 \\
\hline 41 & \multirow{5}{*}{9} & 100 & 0.60 & 0.020 & 0.276 & 1200 \\
\hline 42 & & 100 & 0.60 & 0.040 & 0.527 & 2400 \\
\hline 43 & & 100 & 0.60 & 0.080 & 0.950 & 4800 \\
\hline 44 & & 100 & 0.60 & 0.160 & 1.916 & 9600 \\
\hline 45 & & 100 & 0.60 & 0.320 & 3.807 & 19200 \\
\hline 46 & \multirow{5}{*}{10} & 100 & 0.75 & 0.020 & 0.416 & 1500 \\
\hline 47 & & 100 & 0.75 & 0.040 & 0.633 & 3000 \\
\hline 48 & & 100 & 0.75 & 0.080 & 1.057 & 6000 \\
\hline 49 & & 100 & 0.75 & 0.160 & 1.916 & 12000 \\
\hline 50 & & 100 & 0.75 & 0.320 & 3.891 & 24000 \\
\hline 51 & \multirow{5}{*}{11} & 125 & 0.15 & 0.020 & 0.112 & 375 \\
\hline 52 & & 125 & 0.15 & 0.040 & 0.237 & 750 \\
\hline 53 & & 125 & 0.15 & 0.080 & 0.728 & 1500 \\
\hline 54 & & 125 & 0.15 & 0.160 & 1.585 & 3000 \\
\hline 55 & & 125 & 0.15 & 0.320 & 3.495 & 6000 \\
\hline 56 & \multirow{5}{*}{12} & 125 & 0.30 & 0.020 & 0.170 & 750 \\
\hline 57 & & 125 & 0.30 & 0.040 & 0.412 & 1500 \\
\hline 58 & & 125 & 0.30 & 0.080 & 0.826 & 3000 \\
\hline 59 & & 125 & 0.30 & 0.160 & 1.843 & 6000 \\
\hline 60 & & 125 & 0.30 & 0.320 & 3.709 & 12000 \\
\hline 61 & \multirow{5}{*}{13} & 125 & 0.45 & 0.020 & 0.203 & 1125 \\
\hline 62 & & 125 & 0.45 & 0.040 & 0.435 & 2250 \\
\hline 63 & & 125 & 0.45 & 0.080 & 0.893 & 4500 \\
\hline 64 & & 125 & 0.45 & 0.160 & 1.902 & 9000 \\
\hline 65 & & 125 & 0.45 & 0.320 & 3.792 & 18000 \\
\hline 66 & \multirow{5}{*}{14} & 125 & 0.60 & 0.020 & 0.292 & 1500 \\
\hline 67 & & 125 & 0.60 & 0.040 & 0.558 & 3000 \\
\hline 68 & & 125 & 0.60 & 0.080 & 1.005 & 6000 \\
\hline 69 & & 125 & 0.60 & 0.160 & 2.028 & 12000 \\
\hline 70 & & 125 & 0.60 & 0.320 & 4.030 & 24000 \\
\hline 71 & \multirow{5}{*}{15} & 125 & 0.75 & 0.020 & 0.441 & 1875 \\
\hline 72 & & 125 & 0.75 & 0.040 & 0.670 & 3750 \\
\hline 73 & & 125 & 0.75 & 0.080 & 1.118 & 7500 \\
\hline 74 & & 125 & 0.75 & 0.160 & 2.028 & 15000 \\
\hline 75 & & 125 & 0.75 & 0.320 & 4.119 & 30000 \\
\hline 76 & \multirow{5}{*}{16} & 150 & 0.15 & 0.020 & 0.123 & 450 \\
\hline 77 & & 150 & 0.15 & 0.040 & 0.254 & 900 \\
\hline 78 & & 150 & 0.15 & 0.080 & 0.783 & 1800 \\
\hline 79 & & 150 & 0.15 & 0.160 & 1.698 & 3600 \\
\hline 80 & & 150 & 0.15 & 0.320 & 3.745 & 7200 \\
\hline 81 & \multirow{5}{*}{17} & 150 & 0.30 & 0.020 & 0.184 & 900 \\
\hline 82 & & 150 & 0.30 & 0.040 & 0.442 & 1800 \\
\hline 83 & & 150 & 0.30 & 0.080 & 0.885 & 3600 \\
\hline 84 & & 150 & 0.30 & 0.160 & 1.974 & 7200 \\
\hline 85 & & 150 & 0.30 & 0.320 & 3.974 & 14400 \\
\hline 86 & \multirow{5}{*}{18} & 150 & 0.45 & 0.020 & 0.218 & 1350 \\
\hline 87 & & 150 & 0.45 & 0.040 & 0.467 & 2700 \\
\hline 88 & & 150 & 0.45 & 0.080 & 0.957 & 5400 \\
\hline 89 & & 150 & 0.45 & 0.160 & 2.038 & 10800 \\
\hline 90 & & 150 & 0.45 & 0.320 & 4.063 & 21600 \\
\hline
\end{tabular}


TABLE 7: Continued.

\begin{tabular}{|c|c|c|c|c|c|c|}
\hline Sample ID & Group & $\begin{array}{l}\text { Cutting speed } \\
(\mathrm{m} / \mathrm{min})\end{array}$ & $\begin{array}{l}\text { Depth of cut } \\
(\mathrm{mm})\end{array}$ & $\begin{array}{l}\text { Feed rate } \\
(\mathrm{mm} / \mathrm{rev})\end{array}$ & $\begin{array}{l}\text { Surface } R_{a} \\
\quad(\mu \mathrm{m})\end{array}$ & $\begin{array}{l}\text { Material removal rate (MRR) } \\
\qquad \mathrm{mm}^{3} / \mathrm{min}\end{array}$ \\
\hline 91 & \multirow{5}{*}{19} & 150 & 0.60 & 0.020 & 0.313 & 1800 \\
\hline 92 & & 150 & 0.60 & 0.040 & 0.598 & 3600 \\
\hline 93 & & 150 & 0.60 & 0.080 & 1.077 & 7200 \\
\hline 94 & & 150 & 0.60 & 0.160 & 2.173 & 14400 \\
\hline 95 & & 150 & 0.60 & 0.320 & 4.318 & 28800 \\
\hline 96 & \multirow{5}{*}{20} & 150 & 0.75 & 0.020 & 0.472 & 2250 \\
\hline 97 & & 150 & 0.75 & 0.040 & 0.718 & 4500 \\
\hline 98 & & 150 & 0.75 & 0.080 & 1.198 & 9000 \\
\hline 99 & & 150 & 0.75 & 0.160 & 2.173 & 18000 \\
\hline 100 & & 150 & 0.75 & 0.320 & 4.413 & 36000 \\
\hline 101 & \multirow{5}{*}{21} & 175 & 0.15 & 0.020 & 0.128 & 525 \\
\hline 102 & & 175 & 0.15 & 0.040 & 0.272 & 1050 \\
\hline 103 & & 175 & 0.15 & 0.080 & 0.832 & 2100 \\
\hline 104 & & 175 & 0.15 & 0.160 & 1.812 & 4200 \\
\hline 105 & & 175 & 0.15 & 0.320 & 3.994 & 8400 \\
\hline 106 & \multirow{5}{*}{22} & 175 & 0.30 & 0.020 & 0.195 & 1050 \\
\hline 107 & & 175 & 0.30 & 0.040 & 0.471 & 2100 \\
\hline 108 & & 175 & 0.30 & 0.080 & 0.945 & 4200 \\
\hline 109 & & 175 & 0.30 & 0.160 & 2.106 & 8400 \\
\hline 110 & & 175 & 0.30 & 0.320 & 4.239 & 16800 \\
\hline 111 & \multirow{5}{*}{23} & 175 & 0.45 & 0.020 & 0.232 & 1575 \\
\hline 112 & & 175 & 0.45 & 0.040 & 0.497 & 3150 \\
\hline 113 & & 175 & 0.45 & 0.080 & 1.021 & 6300 \\
\hline 114 & & 175 & 0.45 & 0.160 & 2.174 & 12600 \\
\hline 115 & & 175 & 0.45 & 0.320 & 4.334 & 25200 \\
\hline 116 & \multirow{5}{*}{24} & 175 & 0.60 & 0.020 & 0.334 & 2100 \\
\hline 117 & & 175 & 0.60 & 0.040 & 0.638 & 4200 \\
\hline 118 & & 175 & 0.60 & 0.080 & 1.149 & 8400 \\
\hline 119 & & 175 & 0.60 & 0.160 & 2.318 & 16800 \\
\hline 120 & & 175 & 0.60 & 0.320 & 4.606 & 33600 \\
\hline 121 & \multirow{5}{*}{25} & 175 & 0.75 & 0.020 & 0.504 & 2625 \\
\hline 122 & & 175 & 0.75 & 0.040 & 0.767 & 5250 \\
\hline 123 & & 175 & 0.75 & 0.080 & 1.278 & 10500 \\
\hline 124 & & 175 & 0.75 & 0.160 & 2.318 & 21000 \\
\hline 125 & & 175 & 0.75 & 0.320 & 4.707 & 42000 \\
\hline
\end{tabular}

creating 125 experiments, among which 110 runs were used in the modeling phase. Prediction of surface roughness was conducted using both a mathematical model built through regression analysis and ANFIS. The predictions from the regression model were then compared to the ANFIS predictions. Fifteen experimental test runs, not included in the regression analysis or in the ANFIS, were used in the validation and comparison of the models. The results illustrate that the ANFIS technique has slightly better accuracy than the regression analysis. The mean absolute error (MAE) of the regression analysis is one order of magnitude higher than the MAE of ANFIS analysis with values of $0.035 \mu \mathrm{m}$ and $0.003 \mu \mathrm{m}$, respectively. Optimization process was run using the desirability function approach to maximize the material removing rate (MRR) while maintaining $R_{a}$ below $0.8 \mu \mathrm{m}$.

\section{Appendix}

See Table 7.

\section{Conflicts of Interest}

The authors declare that they have no conflicts of interest.

\section{Acknowledgments}

Authors would like to thank Twasol Research Excellence Program (TRE Program), King Saud University, Riyadh, Saudi Arabia, for support.

\section{References}

[1] UK ministry of defense report no: DEFSTAN 10-13/2005.

[2] A. T. Abbas, K. Hamza, M. F. Aly, and E. A. Al-Bahkali, "Multiobjective optimization of turning cutting parameters for J-steel material," Advances in Materials Science and Engineering, vol. 2016, Article ID 6429160, 8 pages, 2016.

[3] B. Bhardwaj, R. Kumar, and P. K. Singh, "Surface roughness $\left(\mathrm{R}_{\mathrm{a}}\right)$ prediction model for turning of AISI 1019 steel using 
response surface methodology and Box-Cox transformation," Proceedings of the Institution of Mechanical Engineers, Part B: Journal of Engineering Manufacture, vol. 228, no. 2, pp. 223-232, 2014.

[4] R. Mokhtari Homami, A. Fadaei Tehrani, H. Mirzadeh, B. Movahedi, and F. Azimifar, "Optimization of turning process using artificial intelligence technology," International Journal of Advanced Manufacturing Technology, vol. 70, no. 5-8, pp. 12051217, 2014.

[5] I. Svalina, G. Šimunović, T. Šarić, and R. Lujić, "Evolutionary neuro-fuzzy system for surface roughness evaluation," Applied Soft Computing, vol. 52, pp. 593-604, 2017.

[6] S. Jović, N. Arsić, V. Vukojević, O. Anicic, and S. Vujičić, "Determination of the important machining parameters on the chip shape classification by adaptive neuro-fuzzy technique," Precision Engineering, vol. 48, pp. 18-23, 2017.

[7] T.-L. (Bill) Tsenga, U. Konadaa, and Y. (James) Kwonb, "A novel approach to predict surface roughness in machining operations using fuzzy set theory," Journal of Computational Design and Engineering, vol. 3, no. 1, pp. 1-13, 2016.

[8] G. Kant and K. S. Sangwan, "Predictive modelling and optimization of machining parameters to minimize surface roughness using artificial neural network coupled with genetic algorithm," in Proceedings of the 15th CIRP Conference on Modelling of Machining Operations (CMMO '15), vol. 31, pp. 453-458, June 2015.

[9] K. Raja, P. Marimuthu, and K. Chandrasekaran, "Performance study on AISI316 and AISI410 using different layered coated cutting tools in CNC turning," Journal of Engineering Science and Technology, vol. 10, no. 1, pp. 25-34, 2015.

[10] K. Chandrasekarana, P. Marimuthu, and K. Raja, "Prediction model for CNC turning on AISI316 with single and multilayered cutting tool using Box Behnken Design," International Journal of Engineering, Transactions A: Basics, vol. 26, no. 4, pp. 401-410, 2013.

[11] F. Jafarian, M. Taghipour, and H. Amirabadi, "Application of artificial neural network and optimization algorithms for optimizing surface roughness, tool life and cutting forces in turning operation," Journal of Mechanical Science and Technology, vol. 27, no. 5, pp. 1469-1477, 2013.

[12] D. M. D 'Addona and S. J. Raykar, "Analysis of surface roughness in hard turning using wiper insert geometry," Procedia CIRP, vol. 41, pp. 841-846, 2016.

[13] G. M. A. Acayaba and P. M. D. Escalona, "Prediction of surface roughness in low speed turning of AISI316 austenitic stainless steel," CIRP Journal of Manufacturing Science and Technology, vol. 11, pp. 62-67, 2015.

[14] S. Sahu and B. B. Choudhury, "Optimization of surface roughness using taguchi methodology \& prediction of tool wear in hard turning tools," Materials Today: Proceedings, vol. 2, no. 45, pp. 2615-2623, 2015.

[15] A. Agrawal, S. Goel, W. B. Rashid, and M. Price, "Prediction of surface roughness during hard turning of AISI 4340 steel (69 HRC)," Applied Soft Computing, vol. 30, pp. 279-286, 2015.

[16] M. Azam, M. Jahanzaib, A. Wasim, and S. Hussain, "Surface roughness modeling using RSM for HSLA steel by coated carbide tools," International Journal of Advanced Manufacturing Technology, vol. 78, no. 5-8, pp. 1031-1041, 2015.

[17] M. Mia and N. R. Dhar, "Prediction of surface roughness in hard turning under high pressure coolant using Artificial Neural Network," Measurement: Journal of the International Measurement Confederation, vol. 92, pp. 464-474, 2016.
[18] C. L. He, W. J. Zong, Z. M. Cao, and T. Sun, "Theoretical and empirical coupled modeling on the surface roughness in diamond turning," Materials and Design, vol. 82, pp. 216-222, 2015.

[19] E. A. Al Bahkali, A. E. Ragab, E. A. El Danaf, and A. T. Abbas, "An investigation of optimum cutting conditions in turning nodular cast iron using carbide inserts with different nose radius," Proceedings of the Institution of Mechanical Engineers, Part B: Journal of Engineering Manufacture, vol. 230, no. 9, pp. 1584-1591, 2016.

[20] J.-S. R. Jang, "ANFIS: adaptive-network-based fuzzy inference system," IEEE Transactions on Systems, Man and Cybernetics, vol. 23, no. 3, pp. 665-685, 1993. 

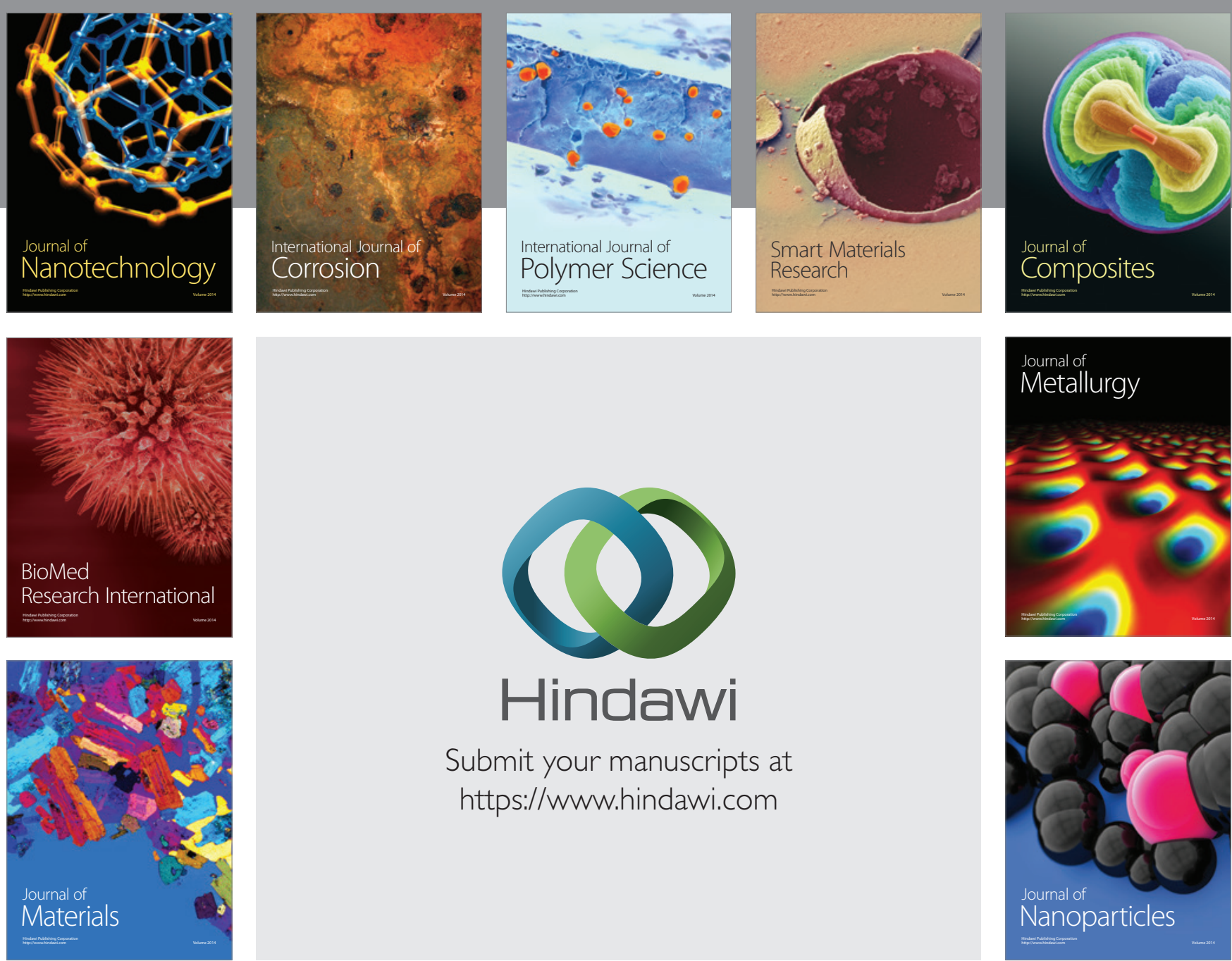

\section{Hindawi}

Submit your manuscripts at

https://www.hindawi.com

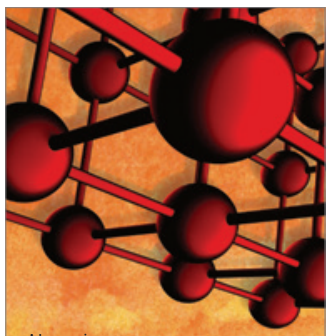

Materials Science and Engineering
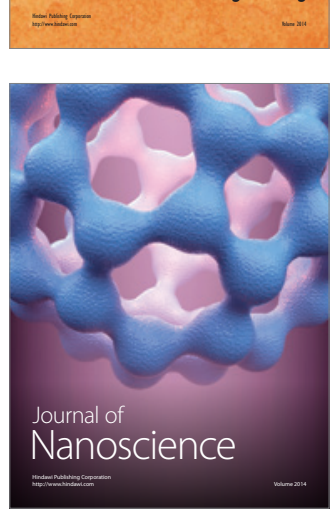
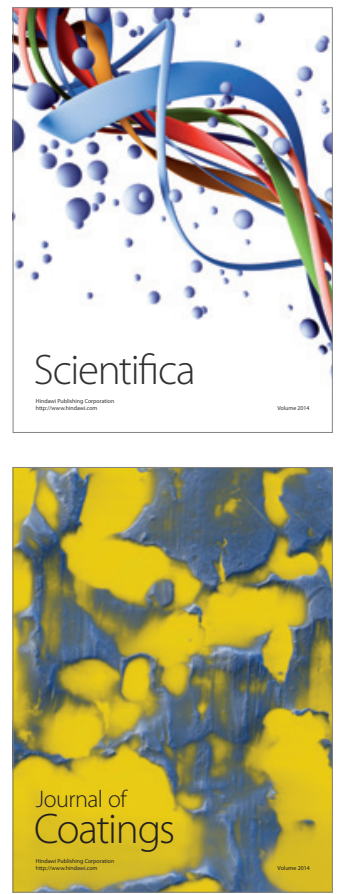
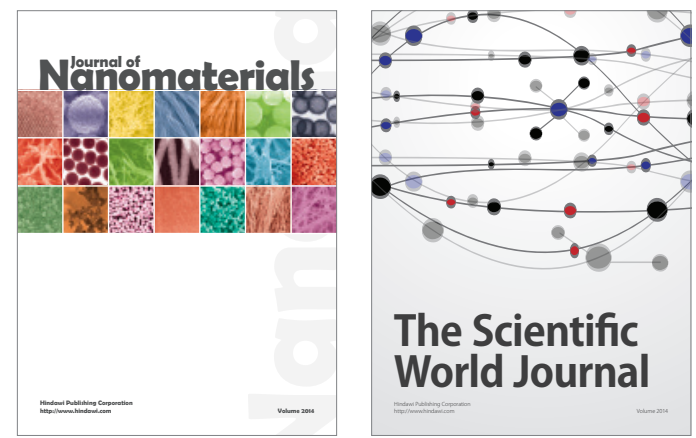

The Scientific World Journal
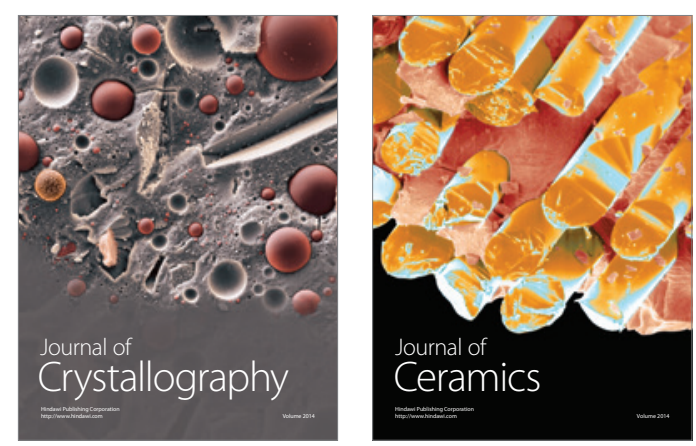
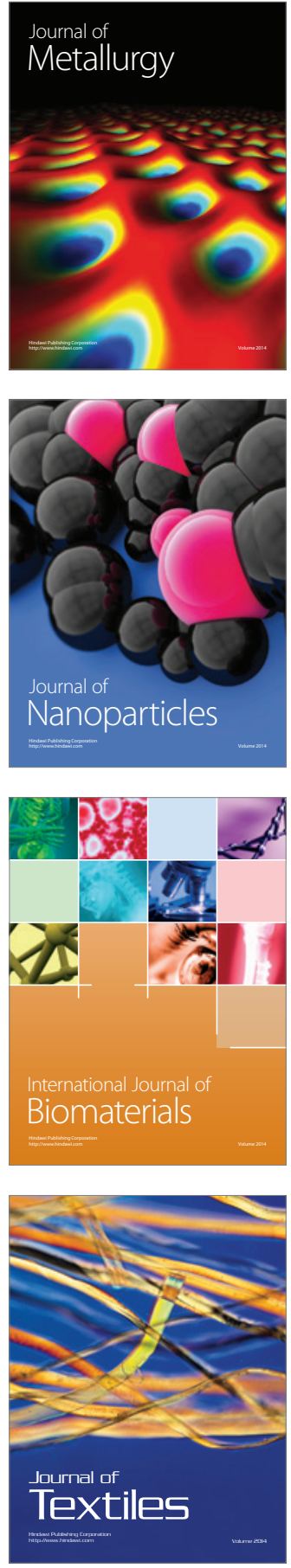